\title{
FOXO3, IRF4, and XIAP Are Correlated with Immune Activation in HIV-1-Infected Men Who Have Sex with Men During Early HIV Infection
}

\author{
Xiaowei Zhang, ${ }^{1,2}$ Zining Zhang, ${ }^{1,2}$ Sijia He, ${ }^{1,2}$ Yajing Fu, ${ }^{1,2}$ Yanhong Chen,,2 Nan Yi,,2 \\ Yongjun Jiang, ${ }^{1,2}$ Wenqing Geng, ${ }^{1,2}$ and Hong Shang ${ }^{1,2}$
}

\begin{abstract}
Forkhead box O (FOXO)1, FOXO3, interferon regulatory factor (IRF)4, X-linked inhibitor of apoptosis protein (xIAP), and E74-like factor (ELF)4 have been described as important regulators of $\mathrm{T}$ cell functions and differentiation. However, whether these molecules are associated with HIV-1 disease progression is still unknown. In this study, we showed that the levels of FOXO3, IRF4, and xIAP mRNA in rapid progressors (RPs) were significantly higher than in HIV-negative healthy controls (HCs). Moreover, FOXO3 expression was positively correlated with HIV-1 viral load and $\mathrm{CD} 4^{+} \mathrm{T}$ cell activation. Remarkably, increased $\mathrm{CD} 4^{+}$and $\mathrm{CD} 8^{+}$ T cell activation was apparent in RPs compared with typical progressors and HCs. In addition, a profile of higher apoptosis, more $\mathrm{CD} 8^{+} \mathrm{T}_{\mathrm{EM}}$ cells, and fewer $\mathrm{CD} 4^{+}$and $\mathrm{CD} 8^{+}$Naive $\mathrm{T}$ cells were observed in early HIV infection patients with low $\mathrm{CD} 4^{+} \mathrm{T}$ cell counts. Furthermore, in vitro, IRF4 and xIAP expression was enhanced in peripheral blood mononuclear cells from healthy people following $\mathrm{T}$ cell receptor stimulation. $\mathrm{T}$ cell activation was decreased by treatment with siRNA inhibiting FOXO3, IRF4, and XIAP. Our results show that significantly increased levels of FOXO3, IRF4, and xIAP mRNA in Chinese HIV-1-infected patients were related to $\mathrm{T}$ cell immune activation, implicating them as potential targets for developing new therapeutic avenues to slow down HIV-1 disease progression.
\end{abstract}

Keywords: HIV, molecular biology, T cell immunity, immune activation, HIV in men who have sex with men (MSM)

\section{Introduction}

T HE POPULATION OF MEN who have sex with men (MSM) has become one of the major risk groups for HIV-1 infection in China. ${ }^{1-5}$ Several studies have shown that MSM show a faster disease progression than other HIV-positive populations. $^{6-9}$ Through recruitment and follow-up of a largescale prospective cohort, we found that nearly $1 / 3$ of MSM patients show a rapid decline in their $\mathrm{CD}^{+} \mathrm{T}$ cell counts to below 350 cells $/ \mu$ l within 1 year, becoming rapid progressors (RPs). However, the reason for this rapid decline is unknown.

Previous studies on T cell functions of the RPs were mostly focused on children. ${ }^{10,11}$ Children who were RPs showed a lower response of polyfunctional HIV-1-specific $\mathrm{CD}^{+} \mathrm{T}$ cells, a higher mean percentage of $\mathrm{DR}^{+} \mathrm{CD} 38^{+} \mathrm{CD} 8^{+} \mathrm{T}$ cells, and higher viremia compared to non-RPs, and these findings were associated with faster subsequent disease progression. ${ }^{10,12}$ Research on adult RPs has evidenced that dendritic cell counts ${ }^{13}$ and some miRNAs are associated with a rapid disease progression of HIV. ${ }^{14}$ Pathway enrichment analysis has shown that the deregulated expression genes in RPs were mostly involved in apoptosis pathways. ${ }^{14}$

However, to present, there have been few studies on T cell function in adult RPs. Children have a definite infection time and they show characteristics distinct from those of adults after HIV-1 infection. ${ }^{15,16}$ How $\mathrm{T}$ cell function changes in adult RPs and how these changes are regulated are still unclear and require further discussion.

Recently, Forkhead box O (FOXO)1 and FOXO3, interferon regulatory factor 4 (IRF)4, X-linked inhibitor of apoptosis protein (xIAP), and E74-like factor (ELF)4 were found to play important roles in regulating $\mathrm{T}$ cell differentiation and

\footnotetext{
${ }^{1}$ Key Laboratory of AIDS Immunology of National Health and Family Planning Commission, Department of Laboratory Medicine, The First Affiliated Hospital, China Medical University, Shenyang, China.

${ }^{2}$ Collaborative Innovation Center for Diagnosis and Treatment of Infectious Diseases, Hangzhou, China.
} 
functions. ${ }^{17-24}$ FOXO3 has been reported to be associated with the control of viremia and to slow HIV disease progression of $\mathrm{HIV}^{+}$elite controllers (ECs). IRF4, xIAP, ELF4, and FOXO1 have not been reported upon in HIV-1-infected patients. Whether these molecules regulate $\mathrm{T}$ cell functions and accelerate disease progression in early HIV infection (EHI) is still unclear.

In this article, we prospectively examined the expression of these $\mathrm{T}$ cell function regulating molecules; moreover, we cross sectionally analyzed the relationship between these molecules and HIV-1 viral load, $\mathrm{CD}^{+} \mathrm{T}$ cell counts, and $\mathrm{T}$ cell activation. Our results showed that FOXO3, IRF4, and XIAP were involved in HIV-1 immune activation. The results of our study will be of benefit for the control of HIV disease progression and provide a new direction for the study of HIV pathogenesis.

\section{Materials and Methods}

\section{Human subjects}

EHI was defined as documented HIV-1 acquisition within the past 6 months. ${ }^{25}$ In this study, HIV-1-positive MSM patients with EHI were enrolled. HIV-1-infected MSM in our study were from the prospective MSM cohort established in our laboratory. The exact infection time for acute HIV patients was determined by using a third-generation ELISA antibody test and pooled nucleic acid amplification testing for HIV screening. ${ }^{26}$ The date of infection was estimated on the basis of epidemiological and laboratory results according to the Fiebig classification. ${ }^{27}$ For the quantification of mRNA (FOXO1, FOXO3, IRF4, xIAP, and ELF4) levels and T cell activation measurement, patients were divided into RPs $\left(\mathrm{CD}^{+}{ }^{+} \mathrm{T}\right.$ cell counts $\leq 350$ cells $/ \mu \mathrm{l}$ within 1 year after HIV-1 infection) and typical progressors (TPs) $\left(\mathrm{CD} 4^{+} \mathrm{T}\right.$ cell counts $\geq 500$ cells $/ \mu$ l after a 12 -month follow-up visit). The HIV treatment guidelines of WHO published in June 2013 recommended an earlier start to antiretroviral therapy (ART). The new proposal encouraged all countries to initiate ART if $\mathrm{CD} 4^{+} \mathrm{T}$ cells were $\leq 500$ cells $/ \mathrm{mm}^{3}$ in HIV-infected adults. In response to these guidelines, we vigorously implemented early ART. Most of the patients received ART therapy after we performed the phenotype tests. Therefore, we could not divide them using the same rules as RPs or TPs. Thus, for the detection of $\mathrm{T}$ cell apoptosis, proliferation, and differentiation, patients were divided into two groups according to the $\mathrm{CD} 4^{+} \mathrm{T}$ cell counts at detection time, $\mathrm{CD} 4_{\text {low }}$ group $\left(\mathrm{CD} 4^{+} \mathrm{T}\right.$ cell counts $<449$ cells $/ \mu$ l within 180 days after HIV-1 infection) and $\mathrm{CD} 4_{\text {high }}$ group $\left(\mathrm{CD} 4^{+} \mathrm{T}\right.$ cell counts $>450$ cells $/ \mu \mathrm{l}$ within 180 days after HIV-1 infection). We chose the samples at about 180 days because we intend to look for a predictive marker for disease outcome. None of these patients had received antiretroviral treatment at study entry. Age and gender-matched HIV-1-negative healthy volunteers were used as healthy controls (HCs). The information about infected individuals and controls is shown in Supplementary Table S1 (Supplementary Data are available online at www .liebertpub.com/aid).

Both patients and HCs were obtained from the Key Laboratory of AIDS Immunology of the Ministry of Health, First Affiliated Hospital of China Medical University. All the participants of this study gave written informed consent for their participation in the study.

\section{$C D 4^{+} T$ cell count determination}

$\mathrm{CD}^{+} \mathrm{T}$ cell counts were measured using TriTEST ${ }^{\mathrm{TM}} \mathrm{CD} 4$ FITC/CD8 PE/CD3 perCP reagent (BD Biosciences, Franklin Lakes, NJ) with $50 \mu$ l of anticoagulant-treated whole blood. The quality and accuracy of the $\mathrm{CD}^{+} \mathrm{T}$ cell counts were controlled using Trucount ${ }^{\mathrm{TM}}$ control beads (Becton Dickinson). $\mathrm{CD}^{+} \mathrm{T}$ cell counts were obtained on a FACSCalibur $^{\text {TM }}$ flow cytometer ${ }^{28}$ (Becton Dickinson).

\section{HIV-1 viral load measurement}

Plasma HIV-1 viral loads were measured by standardized real time-PCR (RT-PCR) $\left(\right.$ COBAS $^{\circledR}$ AmpliPrep ${ }^{\circledR} /$ COBAS $^{\circledR}$ TaqMan $^{\circledR}$ ) (Roche Diagnostics, Basel, Switzerland). ${ }^{28}$ The detection range was between 20 and 10,000,000 copies/ml.

\section{PBMCs isolation}

Human peripheral blood mononuclear cells (PBMCs) were isolated from the whole blood of both HIV-infected and healthy volunteers by gradient centrifugation (FicollPaque $^{\mathrm{TM}}$ PLUS; GE Healthcare Bio-Sciences AB, Sweden) at $400 \times g$ for $30 \mathrm{~min}$ at $20^{\circ} \mathrm{C}$ without rotor braking.

\section{mRNA preparation and real-time $P C R$}

FOXO1, FOXO3, IRF4, xIAP, and ELF4 mRNA expression profiles in PBMCs of the patients were measured at about 180 days of HIV infection. Total RNA was extracted from the PBMCs of EHI patients and HCs with an RNeasy ${ }^{\circledR}$ Plus Mini Kit (QIAGEN, Hilden, Germany), and cDNA was synthesized using a PrimeScript ${ }^{\mathrm{TM}}$ RT Reagent Kit (TaKaRa Bio, Otsu, Japan). GAPDH was used as a housekeeping gene to calculate the relative expression of FOXO3, xIAP, IRF4, ELF4, and FOXO1. Primers were designed online as described in Table 1 and were synthesized by BGI, Inc., Beijing, China. SYBR ${ }^{\circledR}$ Green-based real-time quantitative PCR was performed according to the manufacturer's instructions (TaKaRa Bio).

\section{Flow cytometric analysis}

One hundred microliters of whole blood from EHI patients was incubated with the following monoclonal antibodies together for $\mathrm{T}$ cell subsets and the activation assay: FITCCD45RA, perCP-CCR7, ${ }^{29}$ PE-CD38, APC-HLA-DR, ${ }^{30}$ PEcy7-CD3, APC-cy-CD4, or CD8 (BD Biosciences). PBMCs were isolated from the whole blood of EHI patients, and HCs were stained with fluorescence-labeled antibodies-PE-CD3, APC-Cy7-CD4, FITC-CD8, PE-Annexin V, and percpCy5.57-amino-actinomycin (7-AAD) (BD Biosciences)-for T cell apoptosis detection ${ }^{31}$ and with PE-Cy7-CD3, APC-Cy7-CD4, FITC-CD8 (BD Biosciences), and PE-ki67 (BioLegend, San Diego, CA) for $\mathrm{T}$ cell proliferation detection ${ }^{30}$ according to the method described in previous research. ${ }^{32}$ Cells were detected using LSRII flow cytometer (BD Biosciences) and analyzed with FACSDiva ${ }^{\mathrm{TM}}$ Software (BD Biosciences).

\section{PBMCs stimulated by $T$ cell receptor and $m R N A$ level analysis}

For in vitro experiments, PBMCs from HCs were isolated and resuspended with RPMI 1640 medium supplemented with $10 \%(\mathrm{v} / \mathrm{v})$ fetal bovine serum (FBS), $100 \mu \mathrm{g} / \mathrm{ml}$ 
Table 1. Quantitative PCR Primer Sequences

\begin{tabular}{ll}
\hline Sequence name & \multicolumn{1}{c}{ Primer sequence } \\
\hline GAPDH sense primer & $5^{\prime}$-ACATCGCTCAGACACCATG-3' \\
GAPDH antisense primer & $5^{\prime}$-TGTAGTTGAGGTCAATGAAGGG-3' \\
FOXO3 sense primer & $5^{\prime}$-CAGATCTACGAGTGGATGGTG-3' \\
FOXO3 antisense primer & $5^{\prime}$-TCTTGCCAGTTCCCTCATTC-3' \\
XIAP sense primer & $5^{\prime}$-GCACGGATCTTTACTTTTGGG-3' \\
XIAP antisense primer & $5^{\prime}$-GGGTCTTCACTGGGCTTC-3' \\
IRF4 sense primer & $5^{\prime}$-CGTACCAATGTCCCATGACG-3' \\
IRF4 antisense primer & $5^{\prime}$-ACCTTATGCTTGGCTCTGTG-3' \\
ELF4 sense primer & $5^{\prime}$-CTATTACCCTACAGCCCAGTG-3' \\
ELF4 antisense primer & $5^{\prime}$-AGTACAGATGCAGTAAATCAGGG-3' \\
FOXO1 sense primer & $5^{\prime}$-AGACAACGACACATAGCTGG-3' \\
FOXO1 antisense primer & $5^{\prime}$-AGGGAGTTGGTGAAAGACATC-3' \\
\hline
\end{tabular}

PCR conditions were as follows: first was a denaturalization step of $30 \mathrm{~s}$ at $95^{\circ} \mathrm{C}$, second was 40 amplification cycles $\left(95^{\circ} \mathrm{C}\right.$ for $3 \mathrm{~s} ; 60^{\circ} \mathrm{C}$ for $30 \mathrm{~s})$, and a dissociation stage $\left(95^{\circ} \mathrm{C}\right.$ for $15 \mathrm{~s} ; 60^{\circ} \mathrm{C}$ for $1 \mathrm{~min} ; 95^{\circ} \mathrm{C}$ for $15 \mathrm{~s}$ ) as a final step.

streptomycin, and $100 \mathrm{U} / \mathrm{ml}$ penicillin at a concentration of $5 \times 10^{5}$ cells $/ \mathrm{ml}$ in a 96 -well plate incubated with purified NA/LE mouse anti-human CD3 $(3 \mu \mathrm{g} / \mathrm{ml})$ and CD28 $(6 \mu \mathrm{g} /$ $\mathrm{ml}$ ) antibodies (BD Biosciences) for 0, 1, 2, and 3 days. Cells collected on each day were reserved for RT-PCR.

\section{siRNA inhibit gene expression}

Density gradient centrifugation was used to extract PBMCs from HCs. Amaxa ${ }^{\circledR}$ Human T Cell Nucleofector ${ }^{\circledR}$ Kit (Lonza, Basel, Switzerland) was used for siRNA transfection, and a program "U-014" was selected for high viability. The transfected cells were gently transferred into a 12 -well plate and incubated in a $37^{\circ} \mathrm{C} / 5 \% \mathrm{CO}_{2}$ incubator for the next study.

\section{$T$ cell activation and proliferation analysis after inhibiting gene expression}

The transformed cells were stimulated with antiCD3 and antiCD28 antibodies (antiCD3, $3 \mu \mathrm{g} / \mathrm{ml}$, and antiCD28, $6 \mu \mathrm{g}$ / $\mathrm{ml}$; BD Biosciences) in 96-well plates containing $1 \%(\mathrm{v} / \mathrm{v})$ FBS in a final volume of $200 \mu \mathrm{l}$ of media per well. The cells were incubated at $37^{\circ} \mathrm{C}$ with $5 \% \mathrm{CO}_{2}$. Apc-CD8, FITC-CD4, PE-cy7-CD3, and Apc-cy7-CD69 (BD Biosciences) were used for the study of $\mathrm{T}$ cell activation. $\mathrm{T}$ cell proliferation was assessed by staining with Pacific blue-anti-Violet after transfection for $6 \mathrm{~h}$. Then, $5 \times 10^{4}$ cells were counted, added together with the same number of beads (1:1 ratio of cells: beads) into 96-well plates, and cultured for 3 days. Cells were detected using an LSRII flow cytometer (BD Biosciences), and FACSDiva software (BD Biosciences) was used to analyze the data.

\section{Data analysis}

SPSS 17.0 (IBM, Armonk, NY) was used to conduct statistical analysis. One-way ANOVA was used for comparison of expression levels of the tested genes among groups. T cell activation, apoptosis, proliferation, and differentiation profiles were analyzed using one-way ANOVA. Moreover, Bonferroni comparisons were applied for multiple comparisons if there are significant differences between groups by one-way ANOVA analysis. Relationships between immune factors and mRNA levels of the genes were evaluated by Spearman correlation analysis. Paired $T$ tests were used to compare the levels of xIAP, FOXO3, and IRF4 before and after stimulation/siRNA inhibition experiments. $p<.05$ was regarded as statistically significant.

\section{Results}

FOXO3, IRF4, XIAP, FOXO1, and ELF4 expression profiles among different groups

As FOXO1, FOXO3, IRF4, XIAP, and ELF4 have been reported to be very important for T cell survival and function, we examined the expression of those genes among RPs, TPs, and HCs. We isolated PBMCs from the whole blood of EHI patients and $\mathrm{HCs}$ by centrifugation through a Ficoll-Hypaque gradient and quantified the mRNA levels of FOXO1, FOXO3, IRF4, xIAP, and ELF4. We found a significantly higher expression of FOXO3, IRF4, and xIAP in RPs than in HCs $(p=.042, p=.01$; Fig. 1A-C), but there were no significant differences between TPs and HCs, TPs and RPs. Moreover, there was no difference in ELF4 and FOXO1 expression among the groups (Fig. 1D, E).

\section{Relationship between $T$ cell regulatory molecules and HIV-1 disease progression}

We assessed the relationship between the expression of FOXO3, IRF4, xIAP, and CD4 T cell counts and HIV-1 viral load. We found a positive correlation between the level of FOXO3 expression and HIV-1 viral load ( $p=.046, \mathrm{r}=0.552$; Fig. 2B). However, there were no significant correlations between the levels of IRF4, xIAP, and $\mathrm{CD}^{+}{ }^{+} \mathrm{T}$ cell counts and viral load. However, a positive correlation trend appeared between xIAP expression and HIV-1 viral load $(p=.065$, $r=0.487$; Fig. 2B).

\section{Multiple $T$ cell functional changes are associated with faster disease progression}

To investigate the T cell activation profiles of MSM during EHI, we characterized $\mathrm{T}$ cell activation in the RP and TP groups. T cell activation was assessed by measuring coexpression of CD38 with HLA-DR on $\mathrm{CD} 4^{+}$and $\mathrm{CD} 8^{+} \mathrm{T}$ cells. As shown in Figure 3, both $\mathrm{CD}^{+}$and $\mathrm{CD} 8^{+} \mathrm{T}$ cell activation 
FIG. 1. IRF4, FOXO3, and xIAP mRNA expression levels were significantly higher in RPs than in HCs. IRF4, XIAP, FOXO3, FOXO1, and ELF4 mRNA expression levels were detected in PBMCs from $\mathrm{HCs}$, TPs, and RPs. FOXO3 (A), IRF4 (B), and xIAP (C) mRNA expression levels in RPs were significantly higher than those in HCs. ELF4 (D) and FOXO1 (E) mRNA expression levels were not different between groups (HCs, $n=7$; TPs, $n=7$; RPs, $n=8)$. Error bars represent mean \pm SD. $* * * p<.001 ; * * p<.01 ; * p<.05$. HC, healthy control; RP, rapid progressor; $\mathrm{SD}$, standard deviation; TP, typical progressor.

FIG. 2. Correlation between IRF4, xIAP, and FOXO3 mRNA expression levels, $\mathrm{CD}^{+} \mathrm{T}$ cell counts, and HIV-1 viral load. FOXO3 mRNA expression was correlated positively with $\mathrm{CD}^{+} \mathrm{T}$ cell counts (A). The relationship between FOXO3 mRNA expression and HIV-1 viral load (B). The relationship between IRF4 mRNA expression, $\mathrm{CD}^{+} \mathrm{T}$ cell counts $(\mathbf{C})$, and HIV-1 viral load (D). The relationship between xIAP mRNA expression, $\mathrm{CD}^{+} \mathrm{T}$ cell counts (E), and HIV-1 viral load (F) (TPs, $n=7$; RPs, $n=8)$.
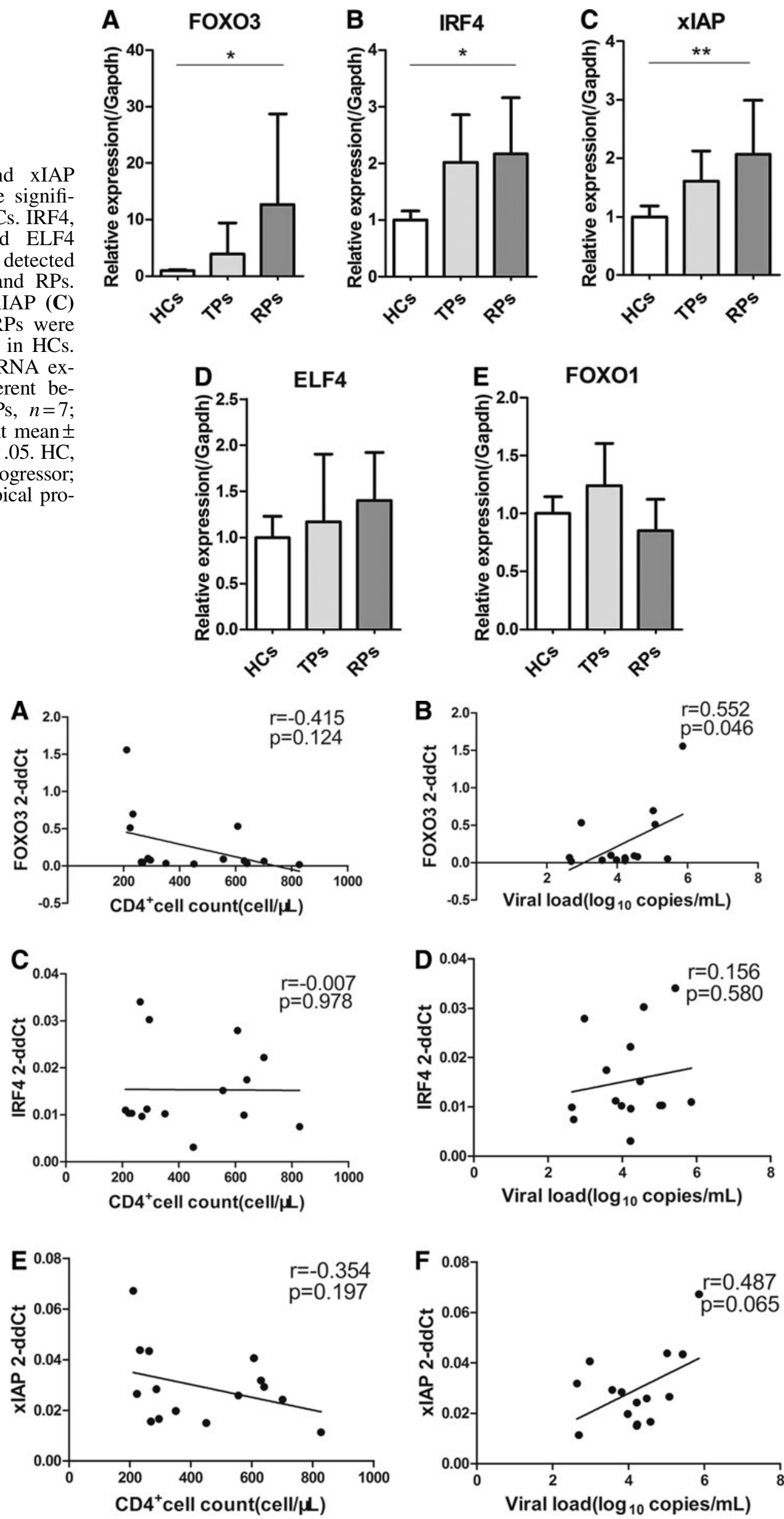
A

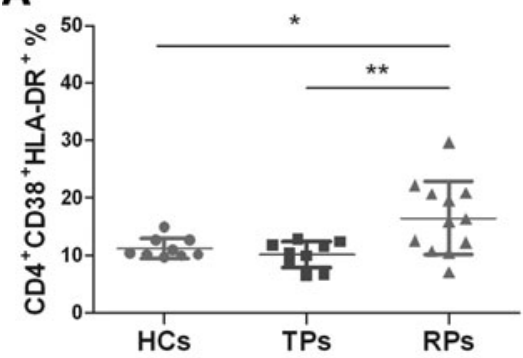

C

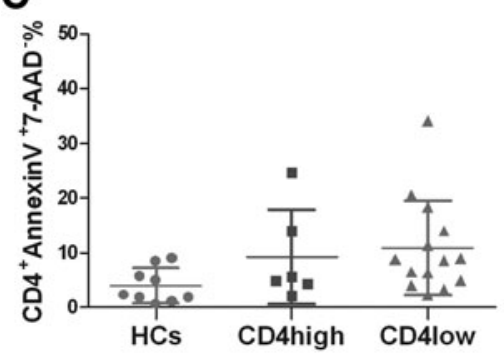

E

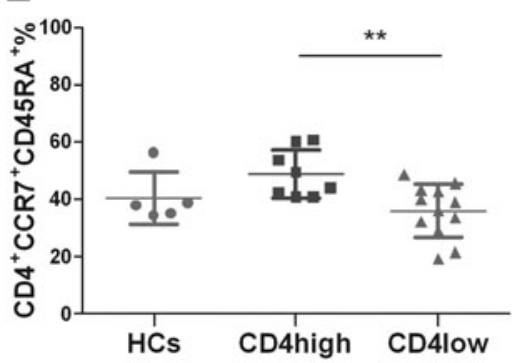

H
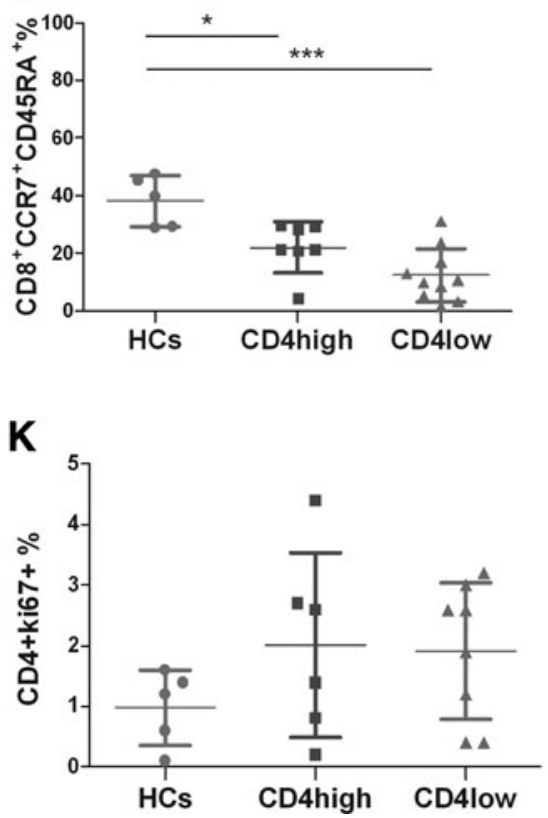

B

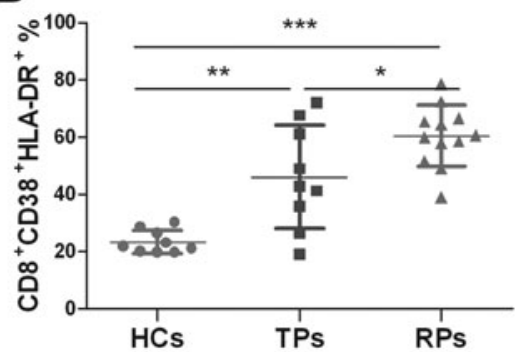

D

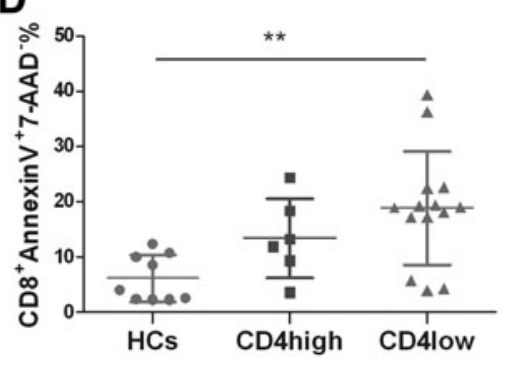

$\mathbf{F}$
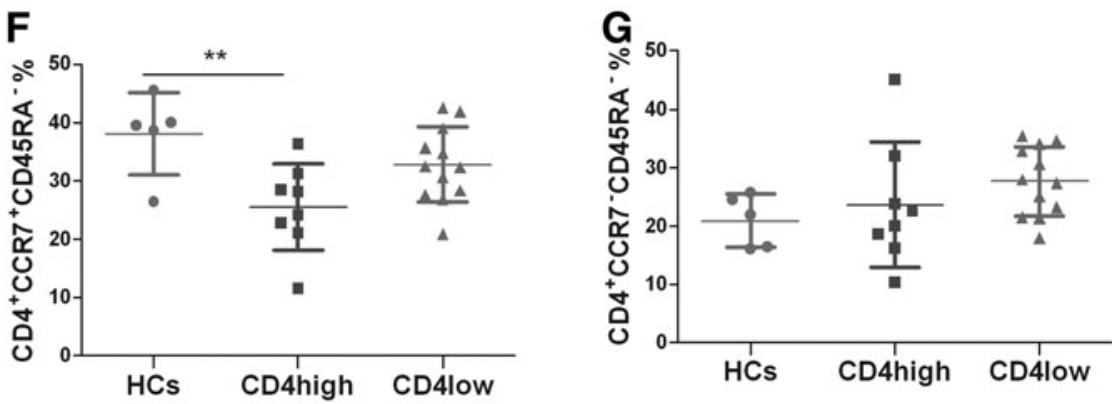

I
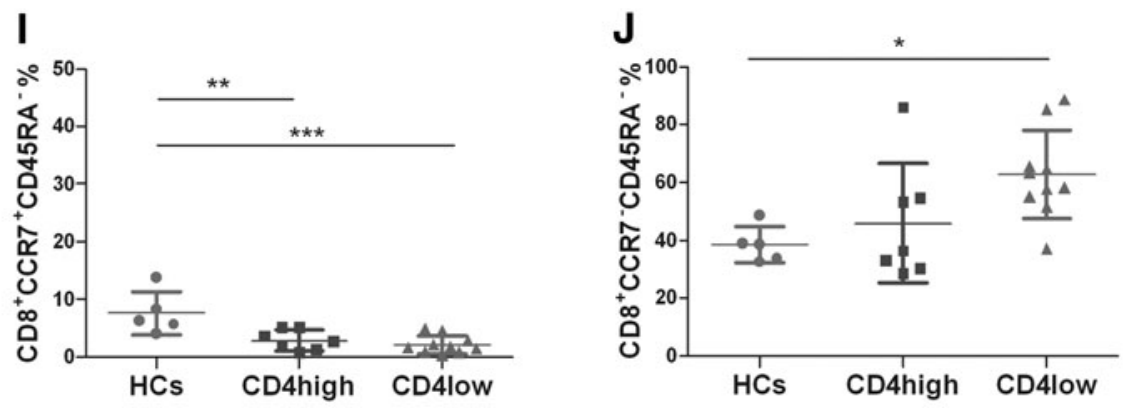

FIG. 3. Comparison of $\mathrm{T}$ cell phenotypes among the three groups. Analysis of $\mathrm{CD} 4^{+}$and $\mathrm{CD} 8^{+} \mathrm{T}$ cell activation $(\mathbf{A}$ and $\mathbf{B})$ (HCs, $n=9$; TPs, $n=9$; RPs, $n=12$ ); apoptosis (C and D) (HCs, $n=9$; CD4 $4_{\text {high }}, n=6$; CD $4_{\text {low }}, n=14$ ); distribution of CD4 ${ }^{+}$ T cell subsets (Naive, $\mathrm{T}_{\mathrm{CM}}$, and $\mathrm{T}_{\mathrm{EM}}$ ) (E-G) (HCs, $n=5$; $\mathrm{CD} 4_{\text {high }}, n=8$; $\mathrm{CD} 4_{\text {low }}, n=12$ ); distribution of $\mathrm{CD} 8^{+} \mathrm{T}$ cell subsets (Naive, $\mathrm{T}_{\mathrm{CM}}$, and $\left.\mathrm{T}_{\mathrm{EM}}\right)(\mathbf{H}-\mathbf{J})\left(\mathrm{HCs}, n=5 ; \mathrm{CD}_{\text {high }}, n=7 ; \mathrm{CD}_{1 \text { low }}, n=10\right)$; and $\mathrm{T}$ cell proliferation $(\mathbf{K}$ and $\mathbf{L})$, (HCs, $n=5$; $\left.\mathrm{CD} 4_{\text {high }}, n=6 ; \mathrm{CD}_{\text {low }}, n=8\right)$. Data points and error bars represent mean $\pm \mathrm{SD}$. $* * * p<.001 ; * * p<.01 ; * p<.05$. 
in RPs were significantly higher than that in HCs $(p=.031$, $p<.001$; Fig. 3A, B). Moreover, $\mathrm{CD}^{+}$and $\mathrm{CD}^{+} \mathrm{T}$ cell activation of RPs was higher compared with TPs $(p=.007$, $p=.013$; Fig. 3A, B).

We also characterized $\mathrm{T}$ cell apoptosis, differentiation, and proliferation in EHI cohorts with low and high $\mathrm{CD}^{+} \mathrm{T}$ cell counts. T cell apoptosis was measured by detecting the levels of AnnexinV $^{+} 7-\mathrm{AAD}^{+} \mathrm{CD}^{+}$and $\mathrm{CD}^{+} \mathrm{T}$ cells. $\mathrm{T}$ cell differentiation was characterized by measuring CD45RA and CCR7 (Naive: $\mathrm{CD}_{45 \mathrm{RA}}{ }^{+} \mathrm{CCR}^{+} \mathrm{CD}^{+} / \mathrm{CD}^{+}, \mathrm{T}_{\mathrm{CM}}$ : $\mathrm{CD} 45 \mathrm{RA}^{-} \mathrm{CCR}^{+}$ $\mathrm{CD}^{+} / \mathrm{CD}^{+}, \mathrm{T}_{\mathrm{EM}}$ : $\left.\mathrm{CD} 45 \mathrm{RA}^{-} \mathrm{CCR}^{-} \mathrm{CD}^{+} / \mathrm{CD}^{+}\right)$. T cell proliferation was assessed by measuring ki67 expression. Then, we measured the levels of $\mathrm{T}$ cell apoptosis among the groups and found that there were statistically significant differences in CD8 $\mathrm{T}$ cell apoptosis between the $\mathrm{CD}_{\text {low }}$ group and $\mathrm{HCs}$ $\left(p=.004\right.$; Fig. 3D). As shown in Figure 3 , the $\mathrm{CD} 4_{\text {low }}$ groups of $\mathrm{CD}^{+}$Naive $\mathrm{T}$ cells showed a significantly lower percentage than the CD4 high group did ( $p=.012$; Fig. $3 \mathrm{E}$ ), but $\mathrm{CD}^{+} \mathrm{T}_{\mathrm{EM}}$ cells showed a significantly higher percentage than the HCs group did $(p=.035$; Fig. $3 \mathrm{~J})$. Levels of ki67 $7^{+}$expression on $\mathrm{T}$ cells were not significantly different among the groups (Fig. 3K, L).

\section{Correlation between $T$ cell phenotypes, $C D 4^{+} T$ cell counts, and HIV-1 viral load}

As RPs and $\mathrm{CD}_{4}$ low group showed distinct $\mathrm{CD} 4^{+} / \mathrm{CD}^{+} \mathrm{T}$ cell activation, apoptosis, and differentiation, we investigated the potential relationships between $\mathrm{CD}^{+} / \mathrm{CD}^{+} \mathrm{T}$ cell phenotypes, $\mathrm{CD}^{+} \mathrm{T}$ cell counts, and HIV-1 viral load. The activation of $\mathrm{CD}^{+} / \mathrm{CD}^{+} \mathrm{T}$ cells was negatively correlated with $\mathrm{CD} 4^{+} \mathrm{T}$ cell counts $(p<.001, \mathrm{r}=-0.690 ; p=.005, \mathrm{r}=-0.587$; Supplementary Fig. S1A, B) and positively correlated with HIV-1 viral load $(p=.021, \mathrm{r}=0.502 ; p=.028, \mathrm{r}=0.478$; Supplementary Fig. S1C, D). CD4 ${ }^{+}$Naive $\mathrm{T}$ cell counts were positively correlated with $\mathrm{CD}^{+} \mathrm{T}$ cell counts $(p=.007, \mathrm{r}=0.523$ Supplementary Fig. 1I), and $\mathrm{CD}^{+}$Naive T cell counts were negatively correlated with viral load $(p=.029, \mathrm{r}=-0.627, \mathrm{~S} 1 \mathrm{R})$. $\mathrm{CD}^{+} \mathrm{T}_{\mathrm{EM}} \mathrm{T}$ cell counts were negatively correlated with $\mathrm{CD} 4^{+}$ T cell counts $(p=.047, \mathrm{r}=-0.488$; Supplementary Fig. $1 \mathrm{~N})$ and positively correlated with viral load $(p=.002, \mathrm{r}=0.797$; Supplementary Fig. 1T). $\mathrm{CD}^{+}$and $\mathrm{CD}^{+} \mathrm{T}$ cell apoptosis was not significantly correlated with CD4 $\mathrm{T}$ cell counts or viral load $(\mathrm{S} 1 \mathrm{E}-\mathrm{H})$.
IRF4, FOXO3, and XIAP expression

is regulated by $T$ cell receptor

RPs showed higher levels of $\mathrm{T}$ cell activation and the $\mathrm{T}$ cell function regulating genes FOXO3, IRF4, and XIAP, it was hypothesized that $\mathrm{T}$ cell activation may be associated with the expression of these genes. Therefore, we discussed in detail the relationship between FOXO3, IRF4, xIAP, and activation of PBMCs from HCs by $\mathrm{T}$ cell receptor (TCR) stimulation. We found that IRF4 and xIAP mRNA expression levels increased with the increasing number of days of stimulation (Fig. 4B, C). However, on the contrary, the reduction in FOXO3 expression was prolonged during the stimulation period (Fig. 4A). These results indicated that IRF4, xIAP, and FOXO3 expression was highly correlated with immune activation.

\section{Inhibiting gene expression (FOXO3/XIAP) impacts $T$ cell activation}

We used siRNA to inhibit the expression of genes in healthy people (the inhibition efficiency of genes is shown in Supplementary Fig. S2). We found that inhibiting FOXO3, XIAP, and IRF4 expression could deregulate $T$ cell activation to different degrees. Inhibiting FOXO3 could significantly reduce the expression of the activation marker CD25 on both $\mathrm{CD}^{+}$and $\mathrm{CD}^{+} \mathrm{T}$ cells $(p=.034, p=.014$; Fig. 5B, C). Inhibiting xIAP significantly reduced the expression of CD25 on $\mathrm{CD}^{+} \mathrm{T}$ cells $(p=.008$; Fig. $5 \mathrm{~F})$, while the expression of $\mathrm{CD} 25$ on $\mathrm{CD}^{+} \mathrm{T}$ cells also decreased ( $p=.057$; Fig. $\left.5 \mathrm{E}\right)$. $\mathrm{CD} 25$ expression on $\mathrm{CD} 4^{+}$and $\mathrm{CD}^{+} \mathrm{T}$ cells decreased after the suppression of IRF4, but this change was not statistically significant (Fig. 5H, I). There was no apparent effect on T cell proliferation of inhibiting FOXO3, IRF4, and xIAP (Supplementary Fig. S3).

\section{Discussion}

In this article, we chose MSM as research subjects because we have established a prospective multicenter and large-scale national cohort; through the continuous recruitment and followup we found that nearly 1/3 of MSM patients becoming RPs. Although viral diversity plays important roles in disease progression, the HIV strain of all eight RPs and six out of seven TP patients in this study was CRF01_AE strain (Supplementary
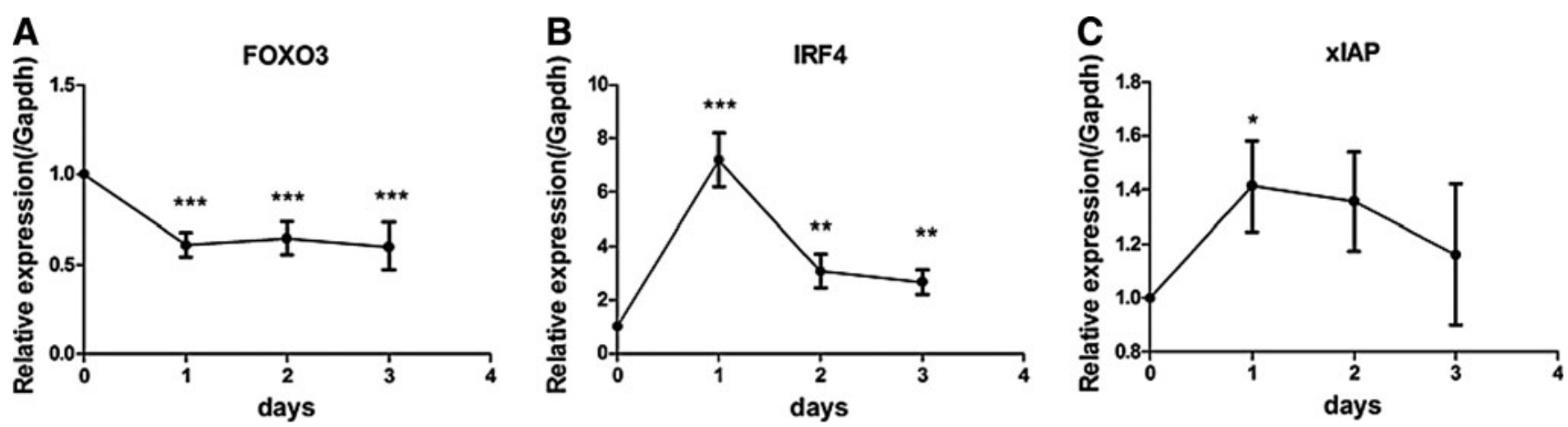

FIG. 4. In vitro, activated PBMCs showed changes in FOXO3, IRF4, and XIAP expression. Stimulation of PBMCs from healthy people with anti-CD3 and anti-CD28 antibodies for different lengths of time resulted in deregulation of FOXO3 expression over time (A), but the expression levels of IRF4 (B) and XIAP (C) increased during the stimulation period $(n=12)$. The results were from three different independent experiments. $* * * p<.001 ; * * p<.01 ; * p<.05$. 

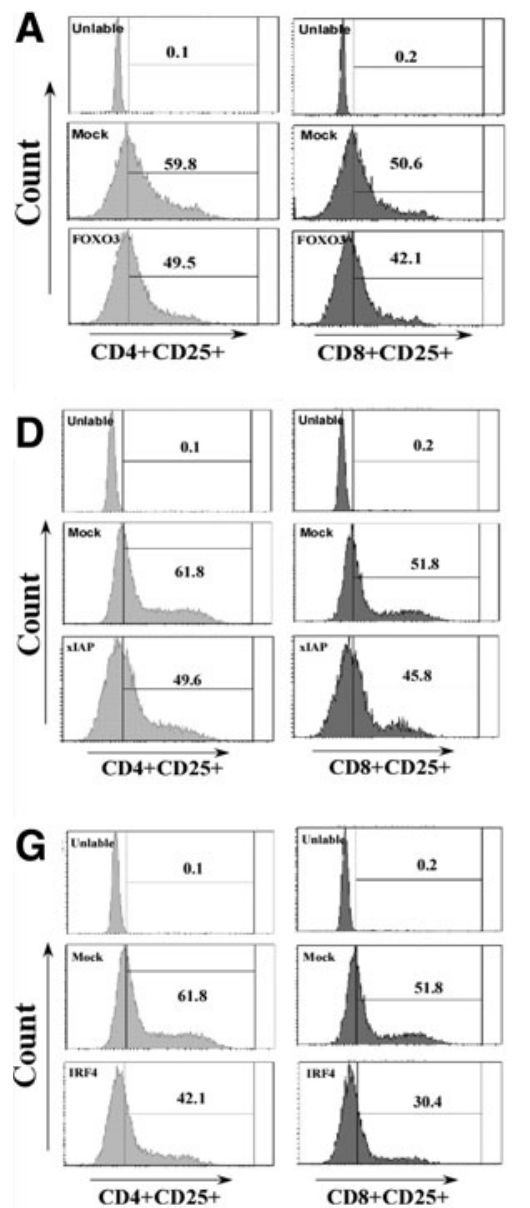

B
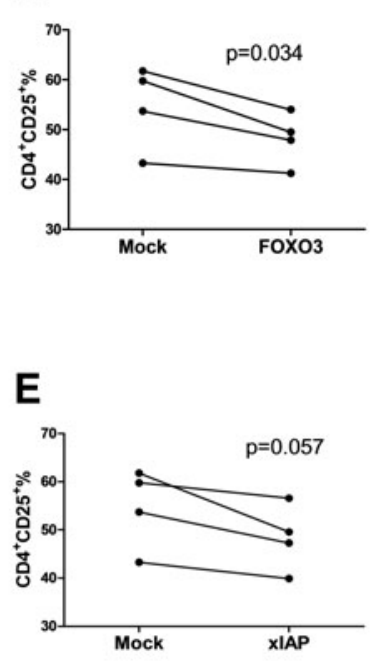

C
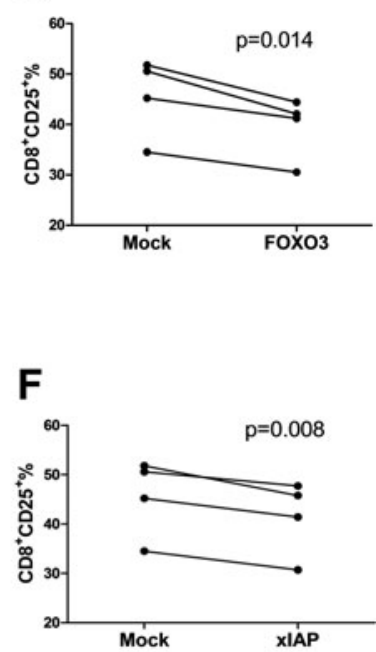

H

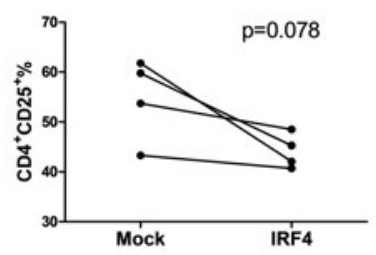

I

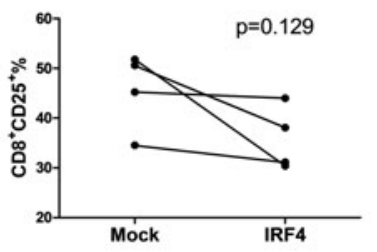

FIG. 5. Inhibiting FOXO3 and xIAP expression influences $T$ cell activation. Small interfering RNA (siRNA) was used to inhibit the expression of FOXO3, xIAP, and IRF4. Inhibiting FOXO3 decreased CD4 ${ }^{+}$and $\mathrm{CD} 8^{+} \mathrm{T}$ cell activation $(\mathbf{B}$ and C). Inhibiting xIAP decreased $\mathrm{CD} 4^{+}$and $\mathrm{CD} 8^{+} \mathrm{T}$ cell activation $(\mathbf{E}$ and $\mathbf{F})$. Inhibiting IRF4 decreased $\mathrm{CD} 4^{+}$and $\mathrm{CD} 8^{+} \mathrm{T}$ cell activation, but these changes did not achieve significance $(\mathbf{H}$ and $\mathbf{I})$. Representative flow cytometry graphs are shown $(\mathbf{A}, \mathbf{D}$, and $\mathbf{G})(n=4)$.

Table S1) and the tropism of HIV isolated from these patients was CCR5 tropic (our unpublished data). These suggest that factors other than viral diversity may play important roles in the different disease progression between RPs and TPs patients. In our study, we quantified the mRNA levels of FOXO3, IRF4, xIAP, FOXO1, and ELF4 in PBMCs from RPs, TPs, and HCs. We provided the first evidence that the mRNA expression levels of FOXO3, IRF4, and XIAP were significantly increased in RPs, compared with those in HCs. Moreover, our data showed that the FOXO3 mRNA level was significantly positively correlated with the HIV-1 viral load ( $p=.046, r=0.552$; Fig. 2$)$ and CD $4^{+}$ $\mathrm{T}$ cell activation $(p=.037, \mathrm{r}=0.736$; Supplementary Fig. $\mathrm{S} 4)$, which further proved that FOXO3 may be associated with HIV1 disease progression. Previous studies indicated that FOXO3 promotes apoptosis, reduces the count of virus-specific $\mathrm{CD}^{+} \mathrm{T}$ cells, ${ }^{24}$ and acts as a negative regulator of the $\mathrm{CD}^{+} \mathrm{T}$ cell response. ${ }^{33}$ These findings remind us that FOXO3 may increase $\mathrm{T}$ cell apoptosis and weaken the $\mathrm{CD}^{+} \mathrm{T}$ cell response to reduce the control of the virus, ultimately accelerating disease progression. IRF4 was reported to be vital for sustaining the expansion and differentiation of effector $\mathrm{CD}^{+} \mathrm{T}$ cells, and IRF4 expression was regulated by the strength of TCR signaling. ${ }^{17}$ In addition, IRF4 can cooperate with activator protein-1 (AP-1), ${ }^{34}$ as AP-1 was considered to be generally involved in T cell ac- tivation $^{35,36}$ and specifically involved in $\mathrm{CD}^{+} \mathrm{T}$ cell activation after HIV-1 infection. ${ }^{37}$ Therefore, we concluded that IRF4 may interact with AP-1 to promote T cell activation, leading to faster disease progression in RPs in our study. Furthermore, our results suggested that a higher expression of XIAP in RPs favors HIV-1 viral replication (HIV-1 viral load was higher in RPs than in TPs, $p<.05$; Supplementary Fig. S5), supporting a recent hypothesis that HIV-1 Tat protein delays apoptosis in $\mathrm{CD}^{+} \mathrm{T}$ cells and favors the persistent replication of HIV-1 in infected cells. ${ }^{38}$ Our results suggested that FOXO3, IRF4, and xIAP play important roles in the rapid progression of HIV by regulating T cell activation, apoptosis, and other functions.

Aberrant T cell activation was associated with HIV disease progression. ${ }^{39} \mathrm{We}$ assessed $\mathrm{T}$ cell function by assessing $\mathrm{T}$ cell activation, apoptosis, differentiation, and proliferation. Our results were consistent with previous reports in children ${ }^{10}$; moreover, we found that not only $\mathrm{CD}^{+}$but also $\mathrm{CD}^{+} \mathrm{T}$ cell activation was significantly increased in RPs and was strongly associated with disease progression. $\mathrm{T}$ cell apoptosis was significantly lower in EHI patients with low CD4 counts than in $\mathrm{HCs}$. In addition, $\mathrm{CD}^{+} \mathrm{T}_{\mathrm{EM}}$ cell counts were sharply increased, whereas $\mathrm{CD}^{+}$Naive and $\mathrm{T}_{\mathrm{CM}}$ counts were significantly decreased in EHI patients with low CD4 counts compared with those in HCs. These changes were significantly correlated 
with HIV disease progression. The above results demonstrated that in the early stage of HIV-1 infection, T cell activation is markedly increased in RPs, and a variety of changes in other $\mathrm{T}$ cell phenotypes were also associated with accelerated disease progression.

There are few studies about FOXO3, IRF4, and XIAP, and immune activation during HIV-1 disease progression. Previous studies of FOXO3, IRF4, and xIAP were mostly focused on apoptosis, survival, cell differentiation using cell lines or mice as a research subject, but few studies on $\mathrm{T}$ cell activation on human primary cell and the exact molecular mechanisms are not very clear. We intended to discuss their function and validated the relationship between higher expression levels of FOXO3, IRF4, and XIAP and T cell activation we found in correlation analysis. We performed in vitro experiments involving TCR stimulation of PBMCs for different time lengths. We found gradual increases of IRF4 and XIAP expression and decreases of FOXO3 expression in a time-dependent manner with prolonged TCR stimulation, verifying that these gene transcripts are associated with $\mathrm{T}$ cell activation. Then, we used siRNA to inhibit the expression of each of these genes. We found that siRNA inhibition of FOXO3 significantly reduced both $\mathrm{CD}^{+}$and $\mathrm{CD}^{+} \mathrm{T}$ cell activation, while inhibition of IRF4 produced nonsignificant trends toward reduction of $\mathrm{CD}^{+}$and $\mathrm{CD}^{+} \mathrm{T}$ cell activation $(p=.057)$. Inhibition of these genes had no significant effect on $\mathrm{T}$ cell proliferation (Supplementary Fig. S3). FOXO3, IRF4, and XIAP may not be the key factors involved in $\mathrm{T}$ cell proliferation as they did in $\mathrm{T}$ cell activation. Interestingly, the results were different when we studied the relationship between FOXO3 and T cell activation, as FOXO3 expression decreased in TCR-stimulated PBMCs, but reduced $\mathrm{T}$ cell activation was also seen with siRNA inhibition of FOXO3. This finding may due to an insufficient length of treatment time or an insufficient sample size for siRNA inhibition experiments, which could be improved in future studies. Moreover, for the TPs, not for RPs (RPs had received ART because their $\mathrm{CD}^{+} \mathrm{T}$ cells were very low and the viral loads were under detection), we analyzed the relationship between gene expression level and viral load after 1 year. We did not find that any of the selected gene expressions was significantly related with VL after 1 year (data not shown). Although the results are not sufficient, it may suggest a role of the selected genes may not affect the viral load. In summary, these results indicated that FOXO3, xIAP, and IRF4 play key roles in $\mathrm{T}$ cell activation.

In conclusion, we demonstrated that the expression levels of FOXO3, IRF4, and XIAP were significantly increased in RPs. Moreover, these genes were involved in $\mathrm{T}$ cell activation during EHI. These findings highlight potential new therapeutic avenues to reduce $\mathrm{T}$ cell activation by targeting IRF4, FOXO3, and XIAP during EHI, which might be beneficial to prevent HIV-1 disease progression.

\section{Acknowledgments}

This work was supported by a research grant, the Mega Projects of National Science Research for the 12th Five-Year Plan (2012ZX10001-006); National Natural Science Foundation of China (81371884) and fundamental and clinical medicine closed union platform-clinical evaluation technology platform of anti-HIV and antineoplastic new drugs (YDFZ-2013-5). The authors thank all of the patients for participating in this study and all of the physicians, nurses, and clinical providers for their help in this study.

\section{Authors' Contributions}

X.Z. designed the experiments, analyzed the data, and wrote the article. Z.Z., S.H., Y.F., and W.G. gave valuable advice in the designing of the experiments. Y.C. and N.Y. participated in the analysis of T cell activation. Z.Z. and Y.J. carried out determination of $\mathrm{CD}^{+} \mathrm{T}$ cell counts. H.S. designed the study with X.Z., verified and helped with interpretation of the data, and contributed to the writing. All authors read and approved the final article.

\section{Author Disclosure Statement}

No competing financial interests exist.

\section{References}

1. Li HM, Peng RR, Li J, et al.: HIV incidence among men who have sex with men in China: A meta-analysis of published studies. PLoS One 2011;6:e23431.

2. Xiao Y, Sun J, Li C, et al.: Prevalence and correlates of HIV and syphilis infections among men who have sex with men in seven provinces in China with historically low HIV prevalence. J Acquir Immune Defic Syndr 2010;53 Suppl 1:S66-S73.

3. Xu JJ, Zhang M, Brown K, et al.: Syphilis and HIV seroconversion among a 12-month prospective cohort of men who have sex with men in Shenyang, China. Sex Transm Dis 2010;37:432-439.

4. Fisher M, Pao D, Brown AE, et al.: Determinants of HIV-1 transmission in men who have sex with men: A combined clinical, epidemiological and phylogenetic approach. AIDS 2010;24:1739-1747.

5. Guo H, Wei JF, Yang H, Huan X, Tsui SK, Zhang C: Rapidly increasing prevalence of HIV and syphilis and HIV-1 subtype characterization among men who have sex with men in Jiangsu, China. Sex Transm Dis 2009;36:120 125.

6. Huang X, Lodi S, Fox Z, et al.: Rate of CD4 decline and HIV-RNA change following HIV seroconversion in men who have sex with men: A comparison between the Beijing PRIMO and CASCADE cohorts. J Acquir Immune Defic Syndr 2013;62:441-446.

7. Xu J, Han X, Reilly KH, Shang H: New features of the HIV epidemic among men who have sex with men in China. Emerg Microbes Infect 2013;2:e45.

8. Gras L, Geskus RB, Jurriaans S, et al.: Has the rate of CD4 cell count decline before initiation of antiretroviral therapy changed over the course of the Dutch HIV epidemic among MSM? PLoS One 2013;8:e64437.

9. Yan H, Yang $\mathrm{H}$, Li J, et al:: Emerging disparity in HIV/ AIDS disease progression and mortality for men who have sex with men, Jiangsu Province, China. AIDS Behav 2014; 18 Suppl 1:S5-S10.

10. Paul ME, Shearer WT, Kozinetz CA, Lewis DE: Comparison of CD8(+) T-cell subsets in HIV-infected rapid progressor children versus non-rapid progressor children. J Allergy Clin Immunol 2001;108:258-264.

11. Resino S, Correa R, Bellon JM, Munoz-Fernandez MA: Preserved immune system in long-term asymptomatic vertically HIV-1 infected children. Clin Exp Immunol 2003; 132:105-112. 
12. Thobakgale CF, Streeck H, Mkhwanazi N, et al.: Short communication: $\mathrm{CD} 8(+) \mathrm{T}$ cell polyfunctionality profiles in progressive and nonprogressive pediatric HIV type 1 infection. AIDS Res Hum Retroviruses 2011;27:1005-1012.

13. Geng W, Fan X, Diao Y, et al.: Rapid disease progression in HIV-1-infected men who have sex with men is negatively correlated with peripheral plasmacytoid dendritic cell counts at the early stage of primary infection. J Clin Immunol 2011;31:882-890.

14. Zhang ZN, Xu JJ, Fu YJ, et al.: Transcriptomic analysis of peripheral blood mononuclear cells in rapid progressors in early HIV infection identifies a signature closely correlated with disease progression. Clin Chem 2013;59:1175-1186.

15. Features of children perinatally infected with HIV-1 surviving longer than 5 years. Italian Register for HIV infection in children. Lancet 1994;343:191-195.

16. Nielsen K, McSherry G, Petru A, et al.: A descriptive survey of pediatric human immunodeficiency virus-infected long-term survivors. Pediatrics 1997;99:E4.

17. Yao S, Buzo BF, Pham D, et al.: Interferon regulatory factor 4 sustains CD8(+) T cell expansion and effector differentiation. Immunity 2013;39:833-845.

18. Gentle IE, Moelter I, Lechler N, et al:: Inhibitors of apoptosis proteins (IAPs) are required for effective T-cell expansion/survival during antiviral immunity in mice. Blood 2014;123:659-668.

19. You F, Wang P, Yang L, et al.: ELF4 is critical for induction of type I interferon and the host antiviral response. Nat Immunol 2013;14:1237-1246.

20. Yamada T, Park CS, Mamonkin M, Lacorazza HD: Transcription factor ELF4 controls the proliferation and homing of CD8+ T cells via the Kruppel-like factors KLF4 and KLF2. Nat Immunol 2009;10:618-626.

21. Kim MV, Ouyang W, Liao W, Zhang MQ, Li MO: The transcription factor Foxo1 controls central-memory CD8+ T cell responses to infection. Immunity 2013;39:286-297.

22. Staron MM, Gray SM, Marshall HD, et al: The transcription factor FoxO1 sustains expression of the inhibitory receptor PD-1 and survival of antiviral CD8(+) T cells during chronic infection. Immunity 2014;41:802-814.

23. van Grevenynghe J, Procopio FA, He Z, et al.: Transcription factor FOXO3a controls the persistence of memory CD4(+) T cells during HIV infection. Nat Med 2008;14: 266-274.

24. Sullivan JA, Kim EH, Plisch EH, Suresh M: FOXO3 regulates the CD8 T cell response to a chronic viral infection. J Virol 2012;86:9025-9034.

25. Streeck H, Jolin JS, Qi Y, et al.: Human immunodeficiency virus type 1-specific CD8+ T-cell responses during primary infection are major determinants of the viral set point and loss of CD4+ T cells. J Virol 2009;83:7641-7648.

26. Han X, Xu J, Chu Z, et al.: Screening acute HIV infections among Chinese men who have sex with men from voluntary counseling \& testing centers. PLoS One 2011;6:e28792.

27. Fiebig EW, Wright DJ, Rawal BD, et al.: Dynamics of HIV viremia and antibody seroconversion in plasma donors: Implications for diagnosis and staging of primary HIV infection. AIDS 2003;17:1871-1879.

28. He S, Zhang Z, Fu Y, et al.: Thymic function is most severely impaired in chronic HIV-1 infection, but individuals with faster disease progression during early HIV-1 infection expressed lower levels of RTEs. J Acquir Immune Defic Syndr 2015;70:472-478.

29. Monteiro M, Evaristo C, Legrand A, Nicoletti A, Rocha B: Cartography of gene expression in CD8 single cells: Novel CCR7- subsets suggest differentiation independent of CD45RA expression. Blood 2007;109:2863-2870.

30. Tincati C, Savoldi A, Cannizzo ES, et al.: T-cell phenotype and function following a first cART regimen containing either a protease inhibitor or a non-nucleoside retrotranscriptase inhibitor in HIV-infected late presenters: Results from a retrospective, ex vivo study. Antivir Ther 2016;21:133-142.

31. Mburu S, Marnewick JL, Abayomi A, Ipp H: Modulation of LPS-induced CD4+ T-cell activation and apoptosis by antioxidants in untreated asymptomatic HIV infected participants: An in vitro study. Clin Dev Immunol 2013;2013:631063.

32. Zaunders JJ, Cunningham PH, Kelleher AD, et al.: Potent antiretroviral therapy of primary human immunodeficiency virus type 1 (HIV-1) infection: Partial normalization of T lymphocyte subsets and limited reduction of HIV-1 DNA despite clearance of plasma viremia. J Infect Dis 1999;180: 320-329.

33. Togher S, Larange A, Schoenberger SP, Feau S: FoxO3 is a negative regulator of primary CD8+ T-cell expansion but not of memory formation. Immunol Cell Biol 2015;93:120-125.

34. Li P, Spolski R, Liao W, et al:: BATF-JUN is critical for IRF4-mediated transcription in T cells. Nature 2012;490: 543-546.

35. Schiefer AI, Vesely P, Hassler MR, Egger G, Kenner L: The role of AP-1 and epigenetics in ALCL. Front Biosci (Schol Ed) 2015;7:226-235.

36. Hayashi K, Altman A. Protein kinase C theta (PKCtheta): A key player in T cell life and death. Pharmacol Res 2007; 55:537-544.

37. Bermejo M, Lopez-Huertas MR, Hedgpeth $\mathrm{J}$, et al:: Analysis of protein kinase $\mathrm{C}$ theta inhibitors for the control of HIV-1 replication in human CD4+ T cells reveals an effect on retrotranscription in addition to viral transcription. Biochem Pharmacol 2015;94:241-256.

38. Lopez-Huertas MR, Mateos E, Sanchez Del Cojo M, et al.: The presence of HIV-1 Tat protein second exon delays fas protein-mediated apoptosis in $\mathrm{CD} 4+\mathrm{T}$ lymphocytes: $\mathrm{A}$ potential mechanism for persistent viral production. J Biol Chem 2013;288:7626-7644.

39. Karim R, Mack WJ, Stiller T, et al:: Association of HIV clinical disease progression with profiles of early immune activation: Results from a cluster analysis approach. AIDS 2013;27:1473-1481.

Address correspondence to: Hong Shang

Key Laboratory of AIDS Immunology of the National Health and Family Planning Commission Department of Laboratory Medicine

The First Affiliated Hospital China Medical University

No. 155, Nanjingbei Street, Heping District

Shenyang

Liaoning Province 110001

China

E-mail: hongshang100@hotmail.com 